\title{
Self-healing materials for space applications: overview of present development and major limitations
}

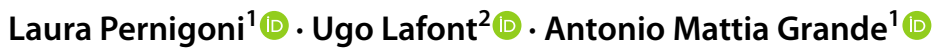

Received: 30 October 2020 / Revised: 22 March 2021 / Accepted: 12 April 2021 / Published online: 21 April 2021

(c) The Author(s) 2021

\begin{abstract}
In the last decade, self-healing materials have become extremely appealing for the field of space applications, due to their technological evolution and the consequent possibility of designing space systems and structures able to repair autonomously after damage arising from impacts with micrometeoroids and orbital debris, from accidental contact with sharp objects, from structural fatigue or simply due to material aging. The integration of these novel materials in the design of spacecraft structures would result in increased reliability and safety leading to longer operational life and missions. Such concepts will bring a decisive boost enabling new mission scenario for the establishment of new orbital stations, settlement on the Moon and human exploration of Mars.

The proposed review aims at presenting the newest and most promising self-healing materials and associated technologies for space application, along with the issues related to their current technological limitations in combination with the effect of the space environment. An introductory part about the outlooks and challenges of space exploration and the self-healing concept is followed by a brief description of the space environment and its possible effects on the performance of materials. Self-healing materials are then analysed in detail, moving from the general intrinsic and extrinsic categories down to the specific mechanisms.
\end{abstract}

Keywords Self-healing $\cdot$ Smart materials $\cdot$ Space materials $\cdot$ Composites $\cdot$ Space environment

\section{Introduction}

Recent innovation in space technologies has significantly increased the feasibility of extended human exploration and colonization missions on the Moon and Mars. For what concerns the Moon, its importance mainly comes from the possibility to create a base on its surface, which could be exploited to prepare to long-term missions towards other planets or celestial bodies, and build necessary skills such

Antonio Mattia Grande

antoniomattia.grande@polimi.it

Laura Pernigoni

laura.pernigoni@polimi.it

Ugo Lafont

ugo.lafont@esa.int

1 Department of Aerospace Science and Technology, Politecnico di Milano, via La Masa 34, 201556 Milan, Italy

2 European Space Research and Technology Centre, European Space Agency, Keplerlaan 1, PO Box 299, 2200 AG Noordwijk, The Netherlands as the creation of essential supplies from in-situ resources [1]. On the other hand, Mars is relatively close and similar to the Earth, and this makes it very appealing both for scientific exploration and for establishment of human settlements. Studies on its evolution and structure may determine whether life exists or existed outside the Earth, and a deeper insight to its geophysics could provide a better understanding of the evolution of other planets in the Solar System [2].

Nevertheless, colonization and exploration missions imply permanence of astronauts and devices in space over long periods, exacerbating the challenges related to the continuous exposure to its hazards and the subsequent degradation of materials, and leading to new strict requirements on the used technologies. Future spacecraft will have to be long lasting, extremely reliable and autonomous, adaptable to a wide range of conditions and requiring minimal maintenance.

To prepare such future mission, it is obvious that the experience gained for the last 20 years on board the International Space Station (ISS) in terms of operational constraints and maintenance is very valuable. For example, on board, 
the ISS there have been several events leading to an internal pressure loss that were related to a breach, crack or hole: in 2004, an air leak in a vacuum jumper hose, in 2018, a leak in Soyuz Orbital Module and recently a leak in Zvezda module that is under investigation. In all cases, astronauts need to spend a consequent amount of time and effort to locate the origin of the damage and find a suitable way to fix it. Focusing on the example of the future Lunar Gateway, the station will always have to remain operational and safe, also during the long periods without astronauts on board. Any occurring damaging events could seriously compromise its functionality and decrease its utility or, in the worst-case scenario, threaten the astronauts' life. When looking at new mission scenario in general, reliability, functionality and safety is of paramount importance and shall be guaranteed trying at the same time to minimise maintenance. Since traditional solutions are unable to adequately match these requirements, new materials and technologies are being considered to ensure long-term survival of space structures in outer space [3]. In particular, the current systems are unable to self-repair, and damage caused by impacts with micrometeoroids and orbital debris (MMOD) could lead to critical failure and total loss of functionality. In this context, self-healing materials have gained visibility as they can give increased reliability and safety and reduced maintenance costs of a spacecraft [3, 4]. Implementing a self-healing mechanism into a design, after being damaged the material would be able to partially or fully restore its main functionality with low to none external intervention, and to almost immediately fix ruptures [5].

\section{Space environment requirements}

To be considered valid substitutes of traditional space technologies, self-healing structures and materials should simultaneously ensure mass and cost savings, increased performances and minimum risk [6]. Nevertheless, depending on the type and length of a mission, exposure to the space environment can cause mechanical, thermal and chemical degradation of the employed materials, with different degrees of severity. To avoid spacecraft failure and ensure proper devices functioning and astronauts' protection [3, 7], the effects of MMOD, temperature fluctuations, radiation, and high vacuum [7] must be considered during the design phase.

Micrometeoroids are small fragments of asteroids or comets having typical velocities around $20 \mathrm{~km} / \mathrm{s}$. On the other hand, debris consists of artificial satellite pieces traveling at speeds in the order of $10 \mathrm{~km} / \mathrm{s}$ [8]. The combination of these two classes is usually indicated with the term MMOD and is characterized by various size ranges. Objects smaller than $1 \mathrm{~mm}$ can lead to thermal surfaces erosion, contamination of optics and surfaces, and leaks in the fuel lines, while
$1 \mathrm{~cm}$ size MMOD may cause fatal damage or even spacecraft destruction $[7,8]$. In general, contact with MMOD or other sharp objects may lead to the space structure depressurization, resulting from the creation of punctures or cuts $[9,10]$. In addition, impacts generate new debris, and other factors as UV radiation, charged particles or thermal cycles can worsen the damage extent $[7,11]$. These issues could be solved through the insertion of self-healing materials into composite and/or multilayer structures used to both protect the spacecraft from impacts and other damaging events and autonomously restore its mechanical properties, hence preserving structural integrity and extending the operating life of the system. Furthermore, while the mass of the resulting systems could be reduced to lower the related launch costs, the structural function would be maintained and safety and reliability would be enhanced [12].

Thermal solicitations represent another fundamental issue. When considering the spacecraft external structure, heat exchange is essentially related to thermal radiation only. Heat sources are represented by the Sun, planets and other celestial bodies, which emit or reflect infrared radiation [13]; on the other hand, space can be represented as a black body acting as a heat sink with respect to the spacecraft. While in orbit around a planet or on its surface, as well as during interplanetary transfer, a space structure is typically subjected to external heat variations, which are often cyclic and typically lead to significant temperature changes and oscillations [14]. As a matter of fact, spacecraft surface temperatures can typically go from $-100{ }^{\circ} \mathrm{C}$ to $100{ }^{\circ} \mathrm{C}$ [7], or even fluctuate between $-120{ }^{\circ} \mathrm{C}$ and $120^{\circ} \mathrm{C}$. High temperature gradients and thermal cycling can hence compromise the strength of materials, which may deform, crack, age or detach from the spacecraft [15]. Uncontrolled thermal conditions negatively affect the spacecraft internal components as well, some of which (e.g., batteries) can operate and survive only within very narrow temperature ranges. Classical thermal control solutions span from passive systems as coatings and multilayer insulation (MLI) to active ones like fluid loops but present some limitations. For instance, MLI blankets used for spacecraft insulation are subjected to atomic oxygen (ATOX) degradation when used in low Earth orbit (LEO) missions [16], and as they are also very fragile [17] their integrity is threatened by the presence of MMOD. The operating life of thermal protection subsystems could be increased through integration of self-healing materials with good ATOX resistance and/or response to temperature solicitations, as they would be able to maintain or restore their chemical, physical and structural properties. As described in Sect. 3, some promising technologies are represented by self-healing ceramics.

Earth's atmosphere is a very efficient shield against harmful radiation from outer space. Here, on the other hand, the absence of this natural protection requires the use of 
artificial shields to prevent irreparable damage to electronics and severe health issues for crewmembers. This problem is also related to celestial bodies different from the Earth; as an example, the radiation dose to which the human body would be subjected on the surface of Mars would be approximately 2.5 times higher than that on the International Space Station (ISS) [18].

Along with damaging electronics, highly energetic radiation as galactic cosmic rays (GCR) can modify the human DNA [19] and trigger material degradation on the spacecraft surface [15]. A second relevant contribution is represented by solar electromagnetic radiation, which includes UV rays and solar particle events (SPE): volatility, mass and energy loss, reduced mechanical performance and thermo-optical properties are among their main effects [11]. Radiation is also a threat for thermal protection components [15], especially the external ones (e.g.: thermal blankets, coatings) [7]. It is also important to underline that space radiation typically possesses a higher energetic content than conventional terrestrial radiation, so relatively low fluxes may anyway generate significant damage. Besides, attempts to reproduce GCR and SPE in terrestrial experiments to quantify the actual material damage are characterized by uncertainty, since particle beams from terrestrial sources might not fully represent space radiation. As a consequence, the dose threshold above which catastrophic material damage is observed is not clearly established, especially concerning new-born self-healing materials and polymers [20]. However, focusing on the less critical case of UV radiation, there already are self-healing solutions against its negative effects, as coatings that even exploit UV rays to initiate crack damage restoration. This leads to a system able not only to autonomously repair, but also to turn a harmful environmental factor into a favourable one [21].

High vacuum interacts with external surfaces and causes material outgassing, which consists in the release of gaseous species from the surface of a material. This phenomenon, typically intensified by high temperatures, is especially relevant in polymers and leads to their chemical modification, corrosion, mass loss and decrease of structural performance, as well as contamination of nearby surfaces and optics. To determine whether a material can be used in space, it is hence required to assess the chemical properties of the outgassing products, the material weight loss, and the amount of contaminating condensed matter. The last two quantities must typically remain below given thresholds that depend on system and mission requirements [22]. Innovative solutions with good vacuum stability are represented by self-healing materials based on syloxanes and vitrimers, which also have good thermal properties and good response to radiation and ATOX environment $[23,24]$. They could hence replace less efficient, classical technologies and combine vacuum resistance with several additional functionalities as damage restoration and ATOX protection.

Focusing on the ATOX factor, polymers are usually highly sensitive to it as well. While ATOX is irrelevant in the lunar and Martian environments, it becomes important in LEO. As ATOX is highly chemically reactive it can induce chemical bond cleavage modifying the electrical, thermal, mechanical and mass properties of the material [16], and eventually leads to its erosion and cracking [15]. A typical solution adopted to protect polymeric materials in LEO environment is to deposit an ATOX-resistant layer on them. However, cracks could be generated on this coating due to impacts with MMOD or thermal cycling, with subsequent exposure of the underlying polymer to ATOX erosion, shortening its service life. This could be avoided thanks to recently proposed thermally stable self-healing ATOXresistant coatings that can autonomously heal mechanical damage and could even exploit ATOX as a trigger for the repairing mechanism [25].

From the considerations made so far, it is clear that the advantages of self-healing materials are not limited to impact protection, as they could in fact significantly improve the spacecraft response and resistance to all space environmental factors. Nevertheless, none of the studies from literature used as a source of information on the here presented self-healing mechanisms satisfactorily analysed the combined and simultaneous effects of space environmental factors on self-healing materials, the lifetime of which is still uncertain [26, 27]. Little information regarding these aspects is currently available, and there is limited evidence of self-healing materials effectiveness in space. Special attention should be paid to the combination of mechanical damage with radiation and vacuum, which could very likely cause impact damage extension and damage rate increase, hence compromising the self-healing performance [11]. In addition, there seem to be no significant tests reproducing the action of GCR and SPE radiation on self-healing materials. A deeper knowledge of these aspects is required to assess the applicability of novel self-healing technologies to a space mission's environment. Furthermore, virtually no self-healing material has been space-qualified or created specifically for space applications. The approach has always been to understand whether materials that were developed for terrestrial purposes could be used in space as well. It is hence necessary to analyse the combined effects of space environment on self-healing materials directly created for space use, conducting tests (both on ground and in space) and simulations that satisfactorily reproduce the complex and simultaneous action of different extra-terrestrial factors as radiation, cryogenic temperature and vacuum.

Consequently, the steps required to increase the technology readiness level (TRL) of the here presented materials and systems are related to quantification of the effects of 
space environment on their physical, mechanical and selfhealing properties. The effects of simulated space environmental factors on microstructure modification and the related microdamage induced in the self-healing materials and systems must be determined. In a first stage, the effects of the following environmental space conditions could be experimentally evaluated: vacuum, UV exposure, protons and electron irradiation, gamma ray irradiation, thermal vacuum cycling. Radiation energy (up to hundred keVlevel) and exposure dose (up to kGy-level) levels caused by GCR and SPE for long-term Moon and Mars mission shall be considered. Accelerated aging and radiation exposure, which might be particularly critical for polymers, also need to be investigated to determine the combined physical aging/ radiation effects on the materials. In particular, simultaneous investigation of the effects of radiation, temperature and vacuum should be performed, along with in-situ spectroscopic measurements to determine material microstructural changes. Conditioned material samples could be then characterized by analytical techniques to measure the influence of simulated space environment on the evolution of the changes in physical and mechanical properties. Processed and conditioned materials could be thus tested and critically compared in terms of self-healing performances.

In a nutshell, in the future years all the research efforts shall be placed into the understanding of the reliability and durability of self-healing systems in space, as well as the definition of efficient testing and screening methodologies to assess their performance after exposure to space environment and aging.

\section{Self-healing systems and materials for space application}

This section describes novel promising self-healing solutions along with recent studies on them and some of their possible applications in space. These self-healing technologies can be classified as either extrinsic or intrinsic. In the first category, a usually liquid healing agent is inserted in a material as a discrete entity, and only single healing events are typically possible. In the second case, on the other hand, the healing ability is inherent in the material due to reversible chemical or physical bonds, and damage restoration can occur several times at the same location [28].

\subsection{Extrinsic mechanisms}

Extrinsic self-healing is typically related to composite materials in which the healing agent is stored inside dedicated containers, such as capsules or vascular networks [28]. A first example is given by the space debris impact protection system proposed in 2012 by Aïssa et al. [8], consisting of a blend of microcapsules containing a monomer, carbon nanotubes (CNTs) and epoxy resin inserted in carbon fibre reinforced polymeric (CFRP) layers. The used healing agents were 5-ethylidene-2-norbornene (5E2N) and dicyclopentadiene (DCPD), and the composite healing performance after hypervelocity impact with MMOD simulants was analysed by hitting seven different material samples with 3-4 mm diameter projectiles simulating space debris traveling at velocities from 4 to $8 \mathrm{~km} / \mathrm{s}$. The obtained mechanical strengths and healing efficiencies ranged respectively from 245 to $326 \mathrm{MPa}$, and 45 to $83 \%$. It was found that the highest mechanical strength was obtained with an equal-weight $5 \mathrm{E} 2 \mathrm{~N}-\mathrm{DCPD}$ blend, and that its healing efficiency was significantly increased through the addition of small quantities of single walled CNTs (SWCNTs). This solution is hence promising for space applications as impact shields with damage restoration properties.

As described in Sect. 2, the presence of MMOD is not the only threat to the spacecraft integrity, as it is combined with many other factors as, for instance, temperature fluctuations. Space self-healing composite ceramics are very appealing in these terms, as they would ensure both thermal protection and autonomous repair. For this reason, they could be used in manufacturing of circuits, thrusters and, in general, space components with strict safety requirements. With the purpose of developing a lightweight self-healing ceramic, Osada et al. [29] incorporated silicon carbide ( $\mathrm{SiC}$ ) healing networks into alumina $\left(\mathrm{Al}_{2} \mathrm{O}_{3}\right)$, and obtained crack healing through $\mathrm{SiC}$ oxidation (Fig. 1). $\mathrm{Al}_{2} \mathrm{O}_{3}$ was chosen as the base material due to its hardness, high resistance to wear, low cost and easy availability [3]. The related self-healing mechanism can be described in this way: the $\mathrm{SiC}$ non-oxide ceramic is inserted into the $\mathrm{Al}_{2} \mathrm{O}_{3}$ oxide ceramic matrix, which prevents its oxidation if damage occurs. When this happens, if $\mathrm{SiC}$ is exposed to sufficiently high temperatures, an oxidation reaction occurs that fills and bonds the damaged surface and leads to full autonomous damage restoration. As just stated, it is important to underline that this process cannot take place at low temperature. To assess the selfhealing performances, a surface crack was introduced by Vickers indentation at the centre of the analysed specimens, which were then healed through heating at $873-1573 \mathrm{~K}$ for $1 \mathrm{~min}$ to $1000 \mathrm{~h}$ in air and tested after complete healing through three-point bending at room temperature. It was found that the material had enhanced self-healing properties and required healing temperatures lower than in aluminosilicates. In a second phase, manganous oxide $(\mathrm{MnO})$ was inserted as an activator to study its ability as a healing accelerator. Results showed that $\mathrm{MnO}$ reduces the required healing time by a factor higher than 6000 and significantly decreases the needed reaction temperature.

Another self-healing ceramic composite, similar to the solution described in [29] and with analogous applications 
a

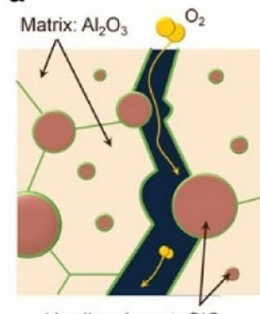

Healing Agent: SiC

$\mathrm{SiC}(\mathrm{s})+3 / 2 \mathrm{O}_{2}(\mathrm{~g})=\mathrm{SiO}_{2}(\mathrm{~s})+\mathrm{CO}(\mathrm{g})$

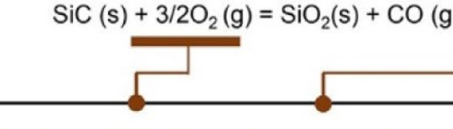

Inflammation stage b

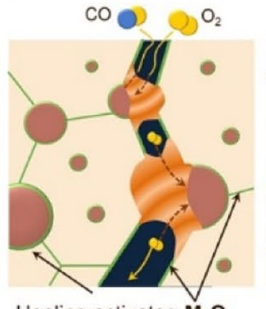

Healing activator: $\mathrm{M}_{\mathrm{x}} \mathrm{O}_{\mathrm{y}}$

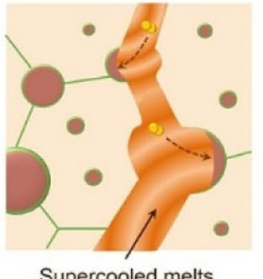

Supercooled melts

$\mathrm{SiO}_{2}(\mathrm{~s})+\mathrm{Al}_{2} \mathrm{O}_{3}(\mathrm{~s})=$ Supercooled melt
$\mathrm{SiO}_{2}(\mathrm{~s})+\mathrm{Al}_{2} \mathrm{O}_{3}(\mathrm{~s})+\mathrm{M}_{\mathbf{x}} \mathrm{O}_{\mathrm{y}}(\mathbf{s})=\mathrm{SiO}_{2}-\mathrm{Al}_{2} \mathrm{O}_{3}-\mathrm{M}_{\mathbf{x}} \mathrm{O}_{\mathrm{y}}$ melt c

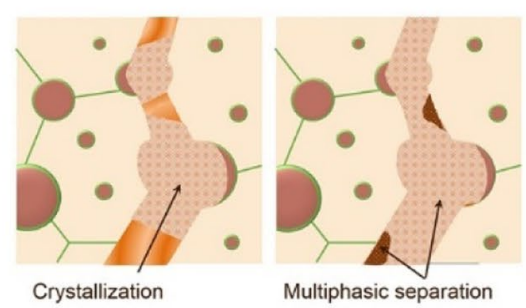

Supercooled melt $=\mathrm{SiO}_{2}$ (cry) + Mullite(cry)

$\mathrm{SiO}_{2}-\mathrm{Al}_{2} \mathrm{O}_{3}-\mathrm{M}_{\mathbf{x}} \mathrm{O}_{\mathbf{y}}$ melt $=$ Crystals

Fig. 1 Self-healing in Al2O3/SiC composites. (a) Oxygen penetrates cracked surfaces and oxidizes $\mathrm{SiC}$ to $\mathrm{SiO} 2$. (b) $\mathrm{Al} 2 \mathrm{O} 3$ and $\mathrm{MxOy}$ dissolve into $\mathrm{SiO} 2$ to form a melt which fills gaps. (c) Mechanically strong crystals nucleate and grow in the supercooled melt [29]

and repair mechanism, was obtained by Boatemaa et al. [30] through the insertion of $10 \mu \mathrm{m}$ titanium (Ti) microparticles inside an $\mathrm{Al}_{2} \mathrm{O}_{3}$ matrix (Fig. 2). Surface cracks could be healed thanks to Ti oxidation, and it was found that complete crack filling was necessary to avoid new ruptures after reloading of the damaged and healed region.

In the experimental characterization, an intentionally generated $100 \mu \mathrm{m}$ long crack was healed at $800{ }^{\circ} \mathrm{C}$ for $4 \mathrm{~h}$, and subsequent SEM analysis showed that the crack was filled with $\mathrm{TiO}_{2}$. Examination of the filling process also proved that healing was characterized by three phases: local bonding of Ti particles, lateral spreading of $\mathrm{TiO}_{2}$ oxide, and complete crack filling. In a configuration with $10 \% \mathrm{Ti}$ volume, cracks with a radius of $20 \mu \mathrm{m}$ and a width below $1 \mu \mathrm{m}$ could be fully filled through annealing at $800{ }^{\circ} \mathrm{C}$ for $1 \mathrm{~h}$ or $900{ }^{\circ} \mathrm{C}$ for $15 \mathrm{~min}$, and complete recovery of the bending strength at room temperature was achieved.

Regarding radiation shielding, on the other hand, an innovative aspect would be to turn this harmful factor into a trigger or enhancer of a self-healing process. An interesting example is given by the microcapsule-based space coating proposed in 2019 by Zhu et al. [21] able to repair in-orbit cracks through self-healing triggered by UV radiation (Fig. 3). Pickering emulsions were polymerized by UV radiation to obtain the capsules, which were then inserted into a silicone resin matrix. The microcapsules had an outer shell made from titanium dioxide $\left(\mathrm{TiO}_{2}\right)$, and an inner polymeric shell. In case of damage, some capsules in the cracked area would break under the action of external forces, while the others would be exposed to space UV radiation and subsequently degrade. The healing agents would hence be released and eventually repair the coating. To determine the anti-aging performance of the coating under long-term radiation, material samples were subjected to an accelerated weathering test by exposing them to UV radiation $\left(310 \mathrm{~nm}, 0.71 \mathrm{~W} / \mathrm{m}^{2}\right)$ for $72 \mathrm{~h}, 144 \mathrm{~h}$, and $216 \mathrm{~h}$. It was observed that, in all the cases, cracks could be still healed after UV light exposure for $12 \mathrm{~h}$.

In a second phase, the UV-responsive self-healing ability of the coating was confirmed through SEM analysis of a sample that had been scratched and exposed to UV radiation $\left(310 \mathrm{~nm}, 582 \mathrm{~W} / \mathrm{m}^{2}\right)$ for $12 \mathrm{~h}$.

Since this concept is related to a dual release mechanism, it is more efficient than classical self-healing capsule
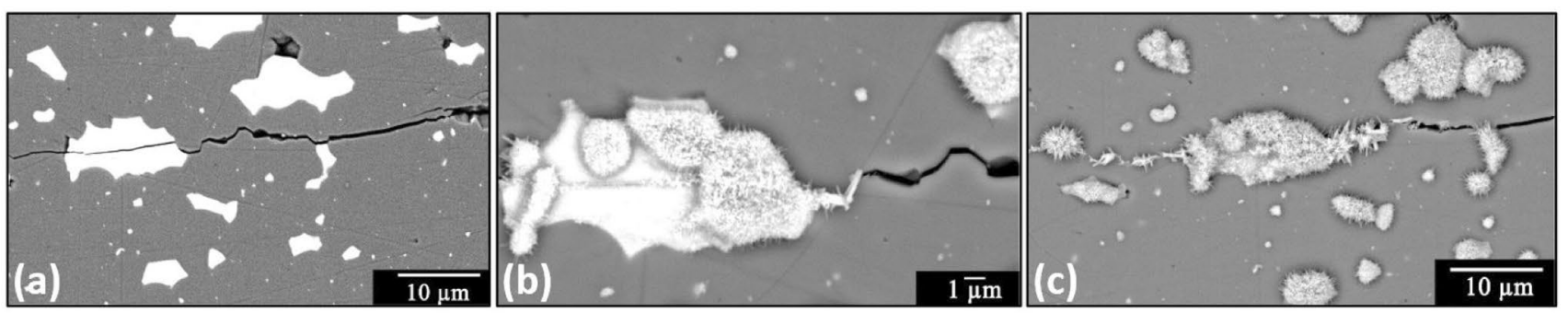

Fig. 2 Crack filling of the Al2O3-Ti composite by oxidation in air at $700{ }^{\circ} \mathrm{C}$ for (a) starting material and after (b) $2 \mathrm{~h}$ and $\mathbf{c} 6 \mathrm{~h}$. Adapted with permission from [30], copyright Elsevier 

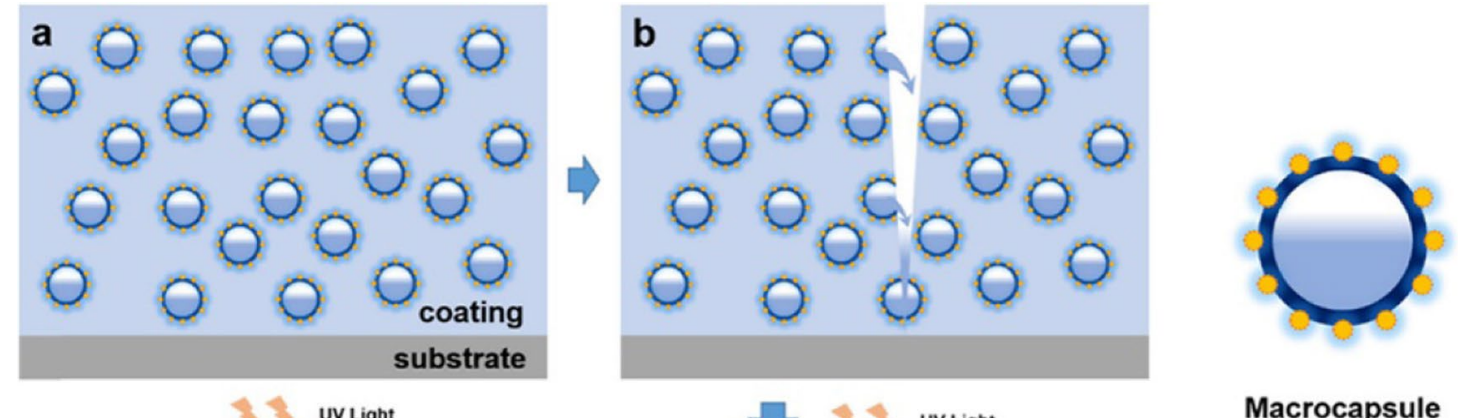

Macrocapsule
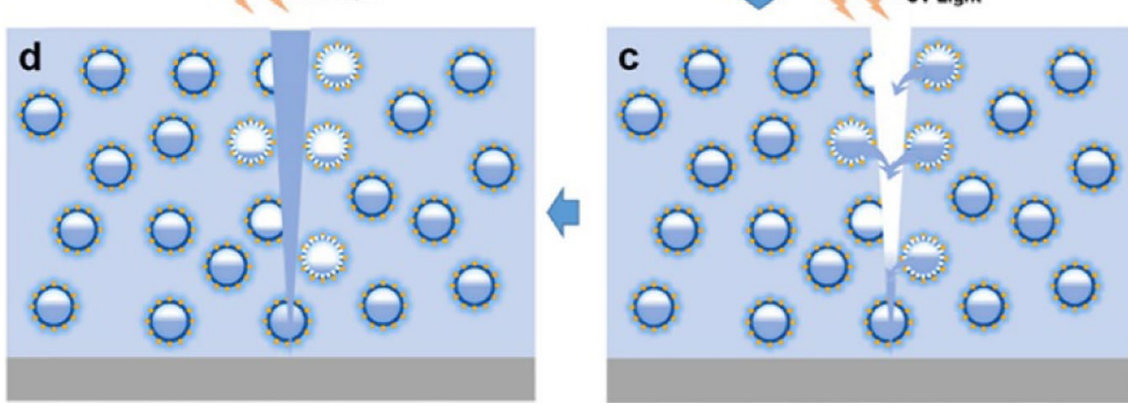

$\mathrm{TiO}_{2}$ nanopaticle

Polymeric shell

Fig. 3 UV-responsive microcapsule system. a Self-healing coating on the substrate. b An external force ruptures some microcapsules. c Unbroken capsules around the crack are degraded by UV radiation.

systems. As previously underlined, harmful UV radiation was used as healing stimulus and transformed into a useful tool to obtain effective healing results [21].

\subsection{Intrinsic mechanisms}

Intrinsic mechanisms do not need healing agents, but typically require external stimuli to activate the self-healing response [28]. Among their several possible applications in space, these mechanisms could be used for impact protection as a valid alternative to the previously described extrinsic solutions or could be even integrated with them. Supramolecular polymers as Reverlink ${ }^{\circledR}$ and ionomers as ethylene/methacrylic acid (EMAA) belong to this family, and Haddad et al. [31] recently combined them with materials as Kevlar ${ }^{\circledR}$ and Nextel ${ }^{\circledR}$ to develop a multilayer impact shield for composite overwrapped pressure vessels (COPVs) (Fig. 4). The focus was set on hypervelocity impacts with small MMOD: aluminium and stainless-steel spheres of 2 to $4 \mathrm{~mm}$ diameter launched at velocities ranging from 1 to $1.7 \mathrm{~km} / \mathrm{s}$ were used to simulate the debris, and optical fibre sensors were integrated into the system to ensure structural health monitoring. Healing through complete hole closure was then verified through vacuum tests at $10^{-6}$ torr and $\mathrm{X}$-ray computed tomography. Promising results were found from the combination of self-healing and strong material layers, underlining the need of further characterisation of (d) Crack is repaired by healing agents. Reprinted with permission from [21], copyright American Chemical Society

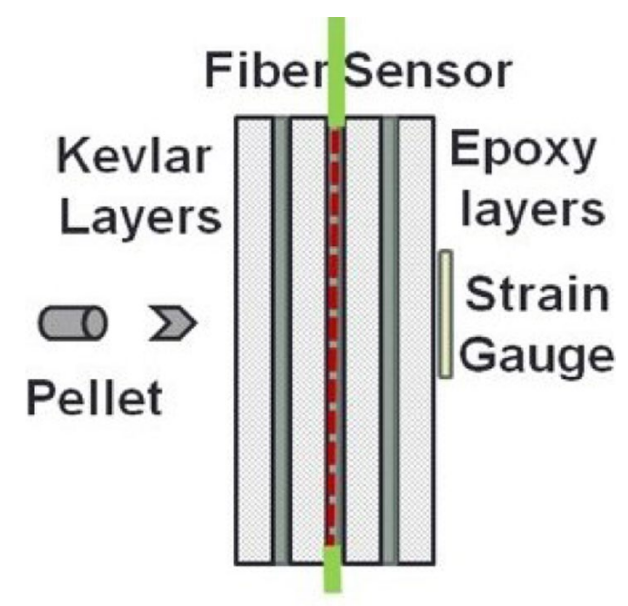

Fig. 4 Example of sample scheme for the COPV impact shield study. [31]

this system both in terms of layup optimization and impact tests at higher velocities.

Several studies were actually carried out on this subject. As a matter of fact, hypervelocity impact tests on EMAA copolymers had been previously performed at the CISAS Hypervelocity Impact Facility in collaboration with Politecnico di Milano: $1.5 \mathrm{~mm}$ aluminium spheres were fired at 1 to $4 \mathrm{~km} / \mathrm{s}$ with a two-stage Light-Gas Gun, demonstrating that these materials maintain their self-healing behaviour also under these impact velocity conditions $[32,33]$. Complete 
healing was reached and healing efficiency was demonstrated both via SEM micrographs and air leakage tests.

High velocity impact tests simulating the action of MMOD were also carried out by NASA on self-healing polymers [12,34] and reactive liquid monomers [35]. The materials analysed in the first case were able to autonomously repair by exploiting the energy generated through collision. No external stimulus was required, indicating that these materials could potentially be used to build self-healing space structures with improved safety and reliability, and longer operating lifetime. The second study, in collaboration with University of Michigan, presented an autonomous healing mechanism based on polymerization of thiol-enetrialkylborane resin triggered by the interaction with oxygen. This mechanism could solve critical or even fatal issues related to breaching in the walls of a pressurised system as a crewed space exploration vehicle or a habitat, since oxygen is widely present in their atmosphere. To assess the feasibility of this application, three-layered panels were manufactured by sandwiching the resin between solid polymer panels and punctured with projectiles traveling at an approximate speed of $1 \mathrm{~km} / \mathrm{s}$ to simulate MMOD impacting on a spacecraft wall. When flowing into the generated hole, the liquid layer reacted with the atmospheric oxygen and started its polymerization, creating a solid plug that sealed the breach and repaired the system. The observed rapid reaction rates demonstrated the potential of this technology, which could be further developed to obtain load-bearing walls which could autonomously heal after multiple impact events, hence preserving the atmosphere inside the spacecraft.

Puncture healing at low velocity was also recently studied focusing on a supramolecular polymer, showing that the polymer had effective self-healing ability also under pressurized conditions [36].

Other materials which may be used in applications dealing with low velocity impact damage are E-glass reinforced polymer composites in which blends of difunctional epoxy monomer and poly ( $\varepsilon$ - caprolactone) (PCL) were used as a self-healing matrix. These composites are characterised by an approximate $50 \%$ fibre volume fraction and can be thermally healed [37]. By treating material samples with a thermal cycle at $150{ }^{\circ} \mathrm{C}$ for $30 \mathrm{~min}$, it was observed that the healing performance increased with the PCL content and the number of healing cycles; $25 \mathrm{vol} \%$ of PCL led to acceptable healing efficiencies without decreasing the composite modulus and strength [38]. Mechanical and healing performances of a novel self-healing composite based on the work presented in $[37,38]$ were also studied with the aim of increasing the lifetime and autonomy of composite structures [39]. Once again, the focus was set on low velocity impacts. A composite system with an epoxy/thermoplastic modified resin was compared with a reference setup through impact tests (ASTM D7136) and compression after impact tests performed to characterize its healing ability. The selfhealing composite showed high healing performance and a $30 \%$ increase of fracture toughness with respect to the reference layup, hence proving to be a promising alternative to common epoxy-based systems.

Another technique to obtain self-healing structural composites for impact or puncture protection in space could be the additive manufacturing of the photoelastomer self-healing ink proposed by $\mathrm{Yu}$ et al. [40], which may also be used to produce soft actuators and self-healing electronics. This 3D printing technology is based on projection microstereolithography, in which the ink polymerizes and solidifies after exposure to a light related to the target geometry. The photocuring rate depends on the amount of thiol groups in the ink, while disulphide groups control the self-healing response. To characterise the self-healing ability of the obtained polymer, dedicated material samples were cut in two and the obtained parts were brought into contact for different healing times $(0-270 \mathrm{~min})$ at $60{ }^{\circ} \mathrm{C}$. The samples were then uniaxially stretched until rupture, and it was observed that their tensile strength gradually increased with the healing time, up to a plateau at approximately $100 \%$ of the original strength after $60 \mathrm{~min}$. In addition, microscopic imaging analysis on a specimen showed that the related crack gap was bridged after $2 \mathrm{~h}$ of healing at $60{ }^{\circ} \mathrm{C}$. Anyway, the most interesting part of this study is related to the subsequent 3D printing and analysis of a self-healing composite in which the previously obtained polymer was combined with a stiff plastic. Tensile tests on previously punctured samples showed crack propagation through the polymer only, with a pattern leading to enhanced toughness with respect to the polymer-only case. Furthermore, the composite was able to recover up to $90 \%$ of its fracture toughness after being healed. Moreover, the used ink showed low sensitivity to moisture (which usually decreases traditional polymers performances), and the related 3D printing technology allows fast manufacturing of objects with complex geometries, excellent self-healing characteristics and good response to fatigue and thermal solicitations in the temperature range from $25{ }^{\circ} \mathrm{C}$ to $165^{\circ} \mathrm{C}$.

In addition to polymers and composites, metals and alloys could be exploited in self-healing structural and electronics space application thanks to the electropulsing treatment, which could be used for localized autonomous repair of these materials [3]. As an example, Yu et al. [41] used electropulsing with a peak current density of $4.1 \mathrm{kA} / \mathrm{mm}^{2}$ under ambient conditions to fix cracks in SUS304 stainless steel, and obtained continuous healed regions on both sides of the cracks after seven discharge repetitions. These regions were characterized by fast melting and solidification, as well as creation of fine recrystallization zones. Electropulsing was also used by Song et al. [42] to initiate healing of a titanium alloy (Fig. 5) The microcracks in the alloy led to a redistribution of currents into concentrated and diluted 
Fig. 5 40,000 $\times$ magnified SEM images of typical microcrack of a damaged Ti alloy sheet (a) before and $\mathbf{b}$ after electropulsing. [42]
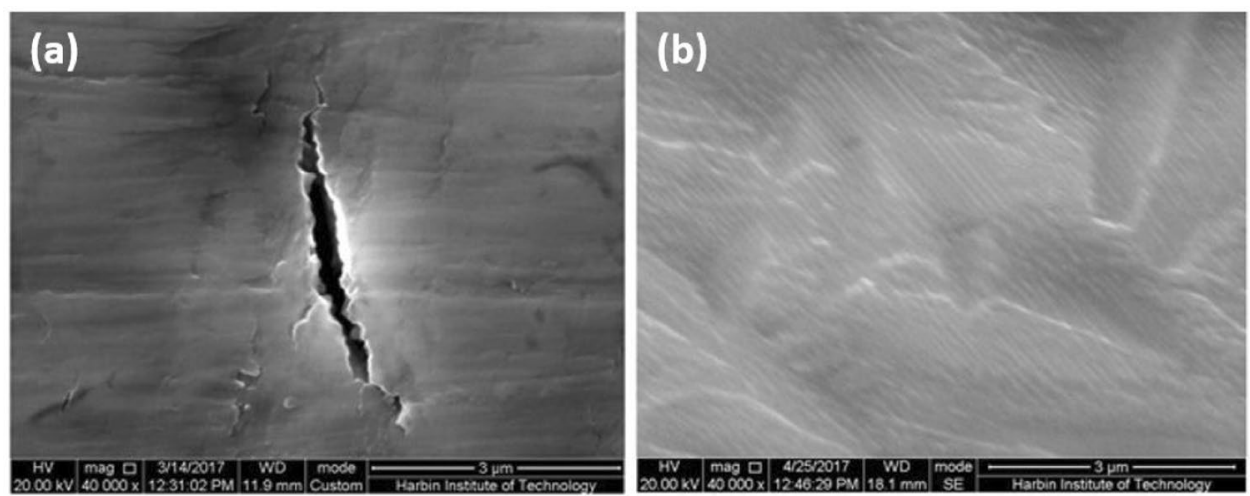

regions, inducing large temperature gradients and compressive stresses, and a subsequent material flow towards the cracks. The additional generation of heat allowed atomic bonding and activated the self-healing process.

Several innovative solutions were also proposed in recent years to overcome the issues related to spacecraft surface degradation in LEO missions due to the action of ATOX.

Wang et al. [25] used ATOX-resistant UPy-POSS supramolecular self-healing polymers to create a protection layer for Kapton ${ }^{\circledR}$, a polyimide. As a matter of fact, polyimides have good flexibility, high stability and low weight, but are subjected to degradation and performance decrease caused by ATOX. When the UPy-POSS layer is added, its exposure to ATOX transforms it into a $\mathrm{SiO}_{2}$ passivating layer that prevents the polyimide degradation (Fig. 6a). The coating also provides increased mechanical strength and thermal stability and autonomous healing (Fig. 6b), which is fundamental in case of damage from MMOD impacts. A ground-based ATOX simulator was used to examine the UPy-POSS coatings: after ATOX exposure of $1.96 \times 10^{20}$ atoms $/ \mathrm{cm}^{2}$ (simulating half a year of ATOX exposure in LEO at $500 \mathrm{~km}$ altitude), SEM analysis showed that the pristine Kapton was eroded by ATOX, while the UPy-POSS-coated Kapton showed no significant change. Furthermore, the mass loss of UPy-POSS-coated Kapton was more than eight times smaller than that of the pristine Kapton. It was also found that the UPy-POSS coatings can heal a maximum crack of approximately $1.1 \mu \mathrm{m}$
Fig. 6 a Working principle of AO-resistant UPy-POSS polymeric coating. b Optical microscope images of the UPy-POSS coating (a) with cracks and (b) after healing at $80^{\circ} \mathrm{C}$ for $2 \mathrm{~min}$. Adapted with permission from [25], copyright Wiley
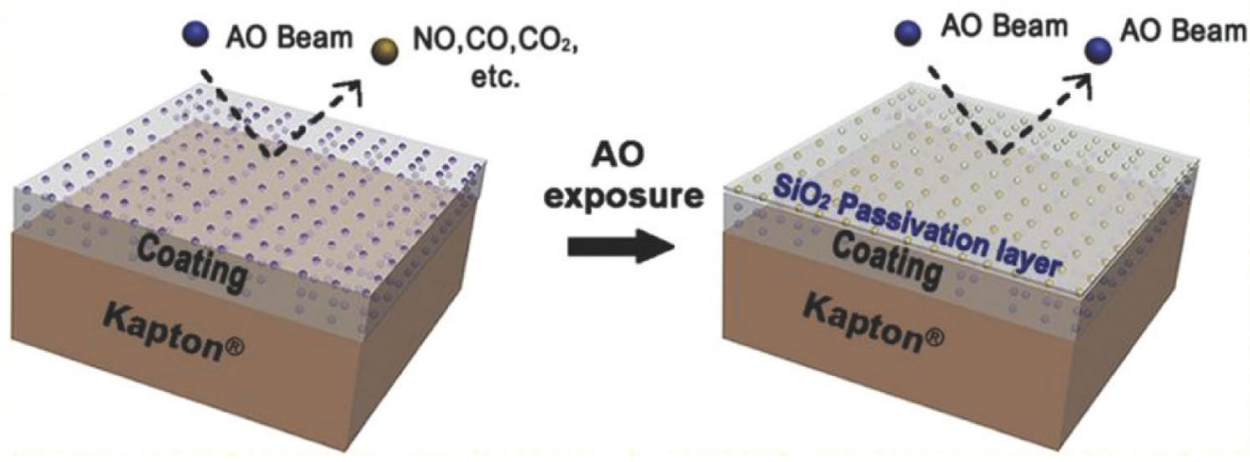

(a)
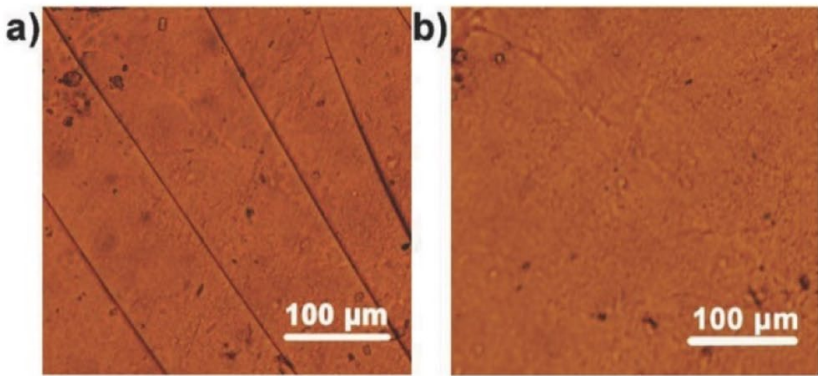

(b) 

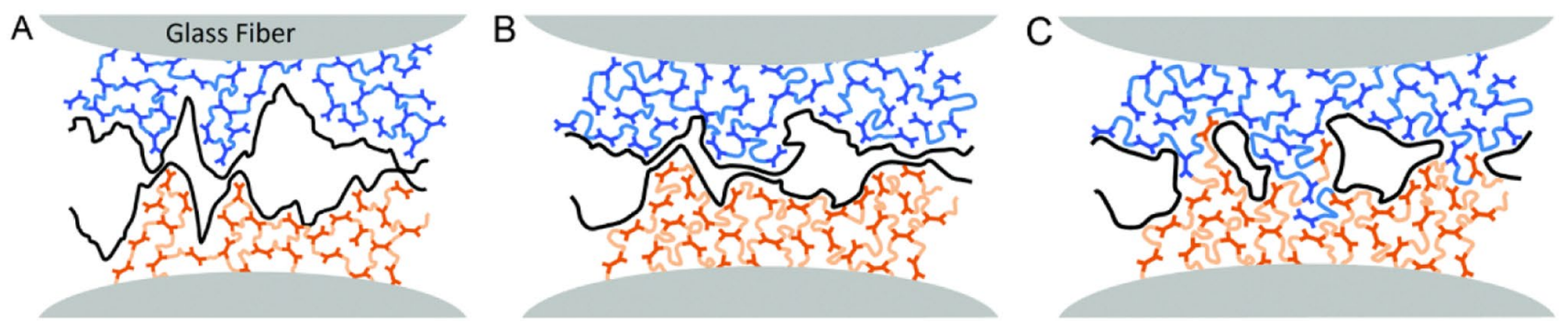

Fig. 7 Schematization of exchange reactions promoting adhesion between vitrimer composite plates. From a to b, exchange reactions enable the matrix to flow and increase surface conformity, promoting the contact between top and bottom adherends. From b to c, top-bottom exchange reactions occur after contact, creating bonds at the interface. Reprinted with permission from [48], copyright Royal Society of Chemistry

of spacecraft resistance to their synergic effects. These materials can simultaneously change their shape and be permanently cross-linked [43], and interest has grown towards the advantages of their self-healing capability for space applications, paving the way towards new perspectives on manufacturing on ground or even out of the Earth, thanks to their thermally triggered reversible bonding ability [44]. Vitrimers which can be processed and recycled multiple times and have high chemical resistance and dimensional stability can be obtained from existing plastics as poly(methyl methacrylate), polystyrene, and high-density polyethylene through mechanisms as the metathesis of dioxaborolanes [45]. Another family of vitrimers is represented by polyhydroxyurethanes (PHUs), which can be reprocessed at high temperatures and pressures without any catalysts and possess repairable networks with high mechanical properties [46]. In general, vitrimers could be used for in-space assembly as adhesives with reversible bonding properties, and they could eventually substitute bolted joints to obtain decreased spacecraft masses. Nevertheless, to be used in space these adhesives would have to satisfy specific requirements [24]: their glass transition temperature should be high enough to ensure mechanical strength under thermal cycling in space, their reversibility properties should be effective in vacuum, and they should be able to resist radiation. In these terms, Meyer et al. [24] performed an interesting study on a vitrimer called aromatic thermosetting copolyester (ATSP), exposing it to proton radiation and ATOX simulating conditions in LEO. Consistent performance and good thermal stability were found along with no relevant modifications to surface chemistry after radiation exposure up to 50 years and suggesting that ASTP could be potentially used as a space adhesive.

Vitrimers can be used as matrix components in self-healing intrinsic polymeric fibre reinforced composites as well $[47,48]$, also because their reshaping and readhesion properties remain effective. An example 12 is given by vinylogous urea vitrimer matrices, which present opportunities for processing, recycle and healing of the related composites, are polymers called vitrimers seems promising for improvement 
appealing for efficient thermal fusion of multiple layers and thermoforming, and have good mechanical properties (glass transition temperature around $110{ }^{\circ} \mathrm{C}$, Young's modulus of 2.2 $\mathrm{GPa}, 70 \mathrm{MPa}$ stress at failure) [47]. The bond strength of a continuous glass fibre reinforced composite plate with a vitrimer matrix was also analysed by Chabert et al. [48], showing its ability to be welded multiple times thanks to the exchange reactions illustrated in Fig. 7.

\section{Conclusions}

Many self-healing materials have been developed in the last years, but few of them were thought and can be used for space applications. Concerning the materials presented in this review, none of them has been qualified for space, and most of the related systems still have a relatively low TRL. One of the main uncertainties is given by whether and how long they will keep their self-healing ability, and how they will degrade when exposed to the complex and combined action of factors as radiation, impacts and ultrahigh vacuum.

Nevertheless, some self-healing materials already show promising applications for space; significant examples are given by materials and composites for ballistic impact protection and with reversible adhesion, reshaping and recycling capability. Since understanding, characterization and modelling of some of the here presented healing mechanisms are currently limited, new approaches are required to study and improve self-healing solutions tailored for future space applications.

To be able to replace traditional space technologies, these new solutions should ensure mass and cost savings, as well as increased performance and minimum risk. Despite still being at an early development stage, their promising characteristics are paving the way for novel space applications that can compete with traditional solutions.

Acknowledgements The authors would like to thank ESA astronaut Alexander Gerst for the valuable discussion regarding ISS impact damage. Dr. Christopher Semprimoschnig is acknowledged for his support and long-lasting effort to enable self-healing concepts for space applications. Financial support from ESA is also acknowledged.

Funding Open access funding provided by Politecnico di Milano within the CRUI-CARE Agreement. ESA Contract No. 4000132669/20/NL/ $\mathrm{MH} / \mathrm{ic}$.

\section{Declarations}

Conflict of interest The authors hereby declare that they have no conflict of interest.

Open Access This article is licensed under a Creative Commons Attribution 4.0 International License, which permits use, sharing, adaptation, distribution and reproduction in any medium or format, as long as you give appropriate credit to the original author(s) and the source, provide a link to the Creative Commons licence, and indicate if changes were made. The images or other third party material in this article are included in the article's Creative Commons licence, unless indicated otherwise in a credit line to the material. If material is not included in the article's Creative Commons licence and your intended use is not permitted by statutory regulation or exceeds the permitted use, you will need to obtain permission directly from the copyright holder. To view a copy of this licence, visit http://creativecommons. org/licenses/by/4.0/.

\section{References}

1. Freeman, O.: Future of Spaceflight, https://www.nationalgeograp hic.com/science/space/space-exploration/future-spaceflight/

2. Why go to Mars?, https://www.esa.int/Science_Exploration/ Human and Robotic_Exploration/Exploration/Why go to Mars

3. Levchenko, I., Bazaka, K., Belmonte, T., Keidar, M., Xu, S.: Advanced materials for next-generation spacecraft. Adv. Mater. 30, 1-13 (2018). https://doi.org/10.1002/adma.201802201

4. Naser, M.Z., Chehab, A.I.: Materials and design concepts for space-resilient structures. Prog. Aerosp. Sci. 98, 74-90 (2018). https://doi.org/10.1016/j.paerosci.2018.03.004

5. ESA: Spacecraft, heal thyself, http://www.esa.int/Enabling_Suppo rt/Preparing_for_the_Future/Discovery_and_Preparation/Space craft_heal_thyself

6. Rawal, S.: Materials and structures technology insertion into spacecraft systems: successes and challenges. Acta Astronaut. 146, 151-160 (2018). https://doi.org/10.1016/j.actaastro.2018. 02.046

7. Gouzman, I., Grossman, E., Verker, R., Atar, N., Bolker, A., Eliaz, N.: Advances in polyimide-base materials for space applications. Adv. Mater. 31, 1-15 (2019). https://doi.org/10.1002/adma.20180 7738

8. Aïssa, B., Tagziria, K., Haddad, E., Jamroz, W., Loiseau, J., Higgins, A., Asgar-Khan, M., Hoa, S.V., Merle, P.G., Therriault, D., Rosei, F.: The Self-healing capability of carbon fibre composite structures subjected to hypervelocity impacts simulating orbital space debris. ISRN Nanomater. (2012). https://doi.org/10.5402/ 2012/351205

9. Ferl, J., Ware, J., Cadogan, D., Yavorsky, J.: Self-healing technology for gas retention structures and space suit systems. SAE Tech. Paper. (2007). https://doi.org/10.4271/2007-01-3211

10. Buslov, E.P., Komarov, I.S., Selivanov, V.V., Titov, V.A., Tovarnova, N.A., Feldstein, V.A.: Protection of inflatable modules of orbital stations against impacts of particles of space debris. Acta Astronaut. 163, 54-61 (2019). https://doi.org/10.1016/j.actaa stro.2019.04.046

11. Grossman, E., Gouzman, I.: Space environment effects on polymers in low earth orbit. Nucl. Instruments Methods Phys. Res. B. 208, 48-57 (2003). https://doi.org/10.1016/S0168-583X(03) 00640-2

12. Gordon, K.L., Siochi, E.J., Yost, W.T., Bogert, P.B., Howell, P.A., Cramer, K.E., Burke, E.R.: Ballistic puncture self-healing polymeric materials. NASA Technical Report NASA/TM-2017219642 (2017)

13. Bedingfield, K.L., Leach, R.D., Alexander, M.B.: Spacecraft system failures and anomalies attributed to the natural space environment. NASA Technical Report NASA-RP-1390 (1996)

14. Lu, Y., Shao, Q., Yue, H., Yang, F.: A review of the space environment effects on spacecraft in different orbits. IEEE Access. 
7, 93473-93488 (2019). https://doi.org/10.1109/ACCESS.2019. 2927811

15. Chen, J., Ding, N., Li, Z., Wang, W.: Organic polymer materials in the space environment. Prog. Aerosp. Sci. 83, 37-56 (2016). https://doi.org/10.1016/j.paerosci.2016.02.002

16. Bitetti, G., Marchetti, M., Mileti, S., Valente, F., Scaglione, S.: Degradation of the surfaces exposed to the space environment. Acta Astronaut. 60, 166-174 (2007). https://doi.org/10.1016/j. actaastro.2006.07.019

17. Hengeveld, D.W., Mathison, M.M., Braun, J.E., Groll, E.A., Williams, A.D.: Review of modern spacecraft thermal control technologies. HVAC R Res. 16, 189-220 (2010). https://doi.org/10. 1080/10789669.2010.10390900

18. Mars Radiation Environment, https://mepag.jpl.nasa.gov/topten. cfm?topten $=10$

19. The radiation showstopper for Mars exploration, https://www.esa. int/Science_Exploration/Human_and_Robotic_Exploration/The_ radiation_showstopper_for_Mars_exploration

20. JM Waller K Rojdev K Shariff DA Litteken RA Hagen 2020 Simulated Galactic Cosmic Ray and Solar Particle Event Radiation Effects on Inflatable Habitat Composite Habitat Space Suit and Space Hatch Cover Materials

21. Zhu, Y., Cao, K., Chen, M., Wu, L.: Synthesis of UV-responsive self-healing microcapsules and their potential application in aerospace coatings. ACS Appl. Mater. Interfaces. 11, 33314-33322 (2019). https://doi.org/10.1021/acsami.9b10737

22. Pastore, R., Delfini, A., Albano, M., Vricella, A., Marchetti, M., Santoni, F., Piergentili, F.: Outgassing effect in polymeric composites exposed to space environment thermal-vacuum conditions. Acta Astronaut. 170, 466-471 (2020). https://doi.org/10.1016/j. actaastro.2020.02.019

23. Fischer, H.R., Tempelaars, K., Kerpershoek, A., Dingemans, T., Iqbal, M., Lonkhuyzen, H.V., Iwanowsky, B., Semprimoschnig, C.: Development of flexible LEO-resistant PI films for space applications using a self-healing mechanism by surface-directed phase separation of block copolymers. ACS Appl. Mater. Interfaces. 2, 2218-2225 (2010). https://doi.org/10.1021/am100223v

24. Meyer, J.L., Lan, P., Pang, S., Chui, K., Economy, J., Jasiuk, I.: Reversible bonding via exchange reactions following atomic oxygen and proton exposure. J. Adhes. Sci. Technol. (2021). https:// doi.org/10.1080/01694243.2021.1876403

25. Wang, X., Li, Y., Qian, Y., Qi, H., Li, J., Sun, J.: Mechanically robust atomic oxygen-resistant coatings capable of autonomously healing damage in low earth orbit space environment. Adv. Mater. 30, 1-7 (2018). https://doi.org/10.1002/adma.201803854

26. Chipara, M., Zaleski, J., Dragnea, B., Shansky, E., Onuta, T., Chipara, M.D.: Self-Healing polymers for space applications. In: 47th AIAA/ASME/ASCE/AHS/ASC Structures, Structural Dynamics and Materials Conference. AIAA, Newport (2006)

27. Trask, R.S., Bond, I.P., Semprimoschnig, C.O.A.: Self-healing of composite structures in a space environment. In: ICCM15-15th International Conference on Composite Materials proceedings. , Durban (2006)

28. Hia, I.L., Vahedi, V., Pasbakhsh, P.: Self-healing polymer composites: prospects, challenges, and applications. Polym. Rev. 56, 225-261 (2016). https://doi.org/10.1080/15583724.2015.1106555

29. Osada, T., Kamoda, K., Mitome, M., Hara, T., Abe, T., Tamagawa, Y., Nakao, W., Ohmura, T.: A novel design approach for selfcrack-healing structural ceramics with 3D networks of healing activator. Sci. Rep. 7, 1-2 (2017). https://doi.org/10.1038/ s41598-017-17942-6

30. Boatemaa, L., van der Zwaag, S., Sloof, W.G.: Self-healing of Al2O3 containing Ti microparticles. Ceram. Int. 44, 11116-11126 (2018). https://doi.org/10.1016/j.ceramint.2018.03.119

31. Haddad, E., Zhao, Y., Celikin, M., Basti, M., Tagziria, K., Wallach, E., Semprimoschnig, C., Lafont, U., McKenzie, I.:
Mitigating the effect of space small debris on COPV in space with fiber sensors monitoring and self-repairing materials. In: Sodnik, Z., Karafolas, N., and Cugny, B. (eds.) ICSO proceedings. ESA and CNES, Chania (2018)

32. Francesconi, A., Giacomuzzo, C., Grande, A.M., Mudric, T., Zaccariotto, M., Etemadi, E., Di Landro, L., Galvanetto, U.: Comparison of self-healing ionomer to aluminium-alloy bumpers for protecting spacecraft equipment from space debris impacts. Adv. Sp. Res. 51, 930-940 (2013). https://doi.org/10.1016/j.asr.2012. 10.013

33. Grande, A.M., Castelnovo, L., Landro, L.D., Giacomuzzo, C., Francesconi, A., Rahman, M.A.: Rate-dependent self-healing behavior of an ethylene-co-methacrylic acid ionomer under highenergy impact conditions. J. Appl. Polym. Sci. (2013). https://doi. org/10.1002/app.39384

34. Gordon, K., Penner, R., Bogert, P., Yost, W.T., Siochi, E.: Puncture Self-healing Polymers for Aerospace Applications. In: 242nd American Chemical Society National Meeting and Exposition (2011)

35. Zavada, S.R., McHardy, N.R., Gordon, K.L., Scott, T.F.: Rapid, puncture-initiated healing via oxygen-mediated polymerization. ACS Macro Lett. 4, 819-824 (2015). https://doi.org/10.1021/ acsmacrolett.5b00315

36. Pernigoni, L., Grande, A.M.: Development of a supramolecular polymer based self-healing multilayer system for inflatable structures. Acta Astronaut. 177, 697-706 (2020). https://doi.org/10. 1016/j.actaastro.2020.08.025

37. Cohades, A., Michaud, V.: Damage recovery after impact in E-glass reinforced poly( $\varepsilon$-caprolactone)/epoxy blends. Compos. Struct. 180, 439-447 (2017). https://doi.org/10.1016/j.compstruct. 2017.08.050

38. Cohades, A., Michaud, V.: Thermal mending in E-glass reinforced poly( $\varepsilon$-caprolactone)/epoxy blends. Compos. Part A Appl. Sci. Manuf. 99, 129-138 (2017). https://doi.org/10.1016/j.compo sitesa.2017.04.013

39. Hostettler, N., Cohades, A., Michaud, V.: Statistical fatigue investigation and failure prediction of a healable composite system. Front. Mater. 7, 561852 (2017). https://doi.org/10.3389/fmats. 2020.561852

40. Yu, K., Xin, A., Du, H., Li, Y., Wang, Q.: Additive manufacturing of self-healing elastomers. NPG Asia Mater. (2019). https://doi. org/10.1038/s41427-019-0109-y

41. Yu, T., Deng, D., Wang, G., Zhang, H.: Crack healing in SUS304 stainless steel by electropulsing treatment. J. Clean. Prod. 113, 989-994 (2016). https://doi.org/10.1016/j.jclepro.2015.12.060

42. Song, H., Wang, Z.J., He, X.D., Duan, J.: Self-healing of damage inside metals triggered by electropulsing stimuli. Sci. Rep. 7, 1-11 (2017). https://doi.org/10.1038/s41598-017-06635-9

43. Denissen, W., Rivero, G., Nicolaÿ, R., Leibler, L., Winne, J.M., Du Prez, F.E.: Vinylogous urethane vitrimers. Adv. Funct. Mater. 25, 2451-2457 (2015). https://doi.org/10.1002/adfm.201404553

44. Meyer, J.L., Bakir, M., Lan, P., Economy, J., Jasiuk, I., Bonhomme, G., Polycarpou, A.A.: Reversible bonding of aromatic thermosetting copolyesters for In-Space assembly. Macromol. Mater. Eng. 304, 1-9 (2019). https://doi.org/10.1002/mame.20180 0647

45. Röttger, M., Domenech, T., Van Der Weegen, R., Breuillac, A., Nicolaÿ, R., Leibler, L.: High-performance vitrimers from commodity thermoplastics through dioxaborolane metathesis. Science 356, 62-65 (2017). https://doi.org/10.1126/science.aah5281

46. Fortman, D.J., Brutman, J.P., Cramer, C.J., Hillmyer, M.A., Dichtel, W.R.: Mechanically Activated, Catalyst-Free Polyhydroxyurethane Vitrimers. J. Am. Chem. Soc. 137, 14019-14022 (2015). https://doi.org/10.1021/jacs.5b08084

47. Denissen, W., De Baere, I., Van Paepegem, W., Leibler, L., Winne, J., Du Prez, F.E.: Vinylogous urea vitrimers and their application 
in fiber reinforced composites. Macromolecules 51, 2054-2064 (2018). https://doi.org/10.1021/acs.macromol.7b02407

48. Chabert, E., Vial, J., Cauchois, J.P., Mihaluta, M., Tournilhac, F.: Multiple welding of long fiber epoxy vitrimer composites. Soft Matter 12, 4838-4845 (2016). https://doi.org/10.1039/c6sm0 $0257 \mathrm{a}$

49. Wu, B., Zhang, Y., Yang, D., Yang, Y., Yu, Q., Che, L., Liu, J.: Self-healing anti-atomic-oxygen phosphorus-containing Polyimide Film via molecular level incorporation of nanocage
Trisilanolphenyl POSS: preparation and characterization. Polymers 11, 1013 (2019). https://doi.org/10.3390/polym11061013

Publisher's Note Springer Nature remains neutral with regard to jurisdictional claims in published maps and institutional affiliations. 